\title{
Extravaginal Testicular Torsion: A Clinical Entity with Unspecified Surgical Anatomy
}

\author{
Iason D. Kyriazis, John Dimopoulos, George Sakellaris, Jurgen Waldschmidt †, George \\ Charissis
}

Department of Pediatric Surgery (IDK, JD, GS, GC), University Hospital of Heraklion, Greece, and Department of Pediatric Surgery (JW, GC), Universitaetsklinikum Benjamin Franklin, Freie Universitaet Berlin, Berlin, Germany

\begin{abstract}
Purpose: To review and evaluate the anatomical definitions of perinatal extravaginal torsion (EVT) of the testis. Materials and Methods: An extensive review of the literature was made to reveal the prevalent anatomical background predisposing to EVT. Gross appearance of twisted testes obtained during surgery for 14 cases of EVT was used to test the validity of the above theories.

Results: The most commonly accepted suggestions describe an EVT within dartos muscle that includes all layers of spermatic cord or an EVT outside parietal layer of tunica vaginalis within internal spermatic fascia. However, both of them were found inadequately documented, while a large volume of controversial data has been accumulated, that raises doubts regarding the validity of such definitions. The gross appearance of twisted testes failed to confirm both an EVT including all layers of the spermatic cord and also an EVT outside tunica vaginalis as possible mechanisms of torsion.

Conclusion: The anatomical basis of EVT remains unclear and further investigation is required.
\end{abstract}

Key words: testis; spermatic cord; anomalous; torsion

Int Braz J Urol. 2008; 34: 617-26

\section{INTRODUCTION}

Extravaginal torsion (EVT) of the testis is reported to be the predominant mechanism of torsion in the fetus and neonate. In this kind of torsion, twist of the spermatic cord is taking place outside the sack of tunica vaginalis in the scrotum. Accordingly, this entity is considered to have a different surgical anatomy, than the one reported in older children and adults who demonstrate the bell clapper deformity and torsion of the testis occurs intravaginally (1). This article reviews and evaluates the current theories on the anatomical basis of EVT given that the low incidence of perinatal torsion and the poorly documented anatomical findings at operation have left surgical anatomy of this clinical entity poorly defined.

\section{MATERIALS AND METHODS}

Photographic data from 14 cases of perinatal testicular torsion, operated by Professor Waldschmidt and Professor Charissis between 1973 and 2006, were examined retrospectively to define the gross appearance of EVT. Moreover, an extensive review of the literature was carried out to reveal the most commonly accepted definitions concerning the surgical anatomy predisposing to EVT. In particular, all related articles appearing in PubMed under the search terms "extravaginal", "perinatal", "testicular torsion" were examined for reference in anatomy of perinatal torsion in addition with referred pathological anatomy of perinatal torsion in text books on Urology and Pediatric Surgery. Finally, evaluation of the proposed

$\dagger$ In memorian 
theories illustrated by our gross appearance photos of the twisted mass was performed.

\section{RESULTS}

\section{Gross Appearance of Extravaginal Torsion}

EVT is considered to be an antenatal event and probably because of the different time intervals between time of torsion and time of observation, gross appearance of twisted mass varies from case to case. However, there were some common characteristics found in all of our cases that can be drawn and described. Our photographic data demonstrated that EVT is usually constituted by a narrow, twisted pedicle that suspends a dark globular mass containing an infracted testis and epididymis, which appears immediately after opening the skin and dartos muscle (Figure-1). Moreover, as histologically evidenced by the most substantiated work on the subject by Herman et al., twisted tissues are surrounded by a smooth membrane layer sequestering an underlying hemorrhage (2) (Figure-2). Moreover, in contrast with

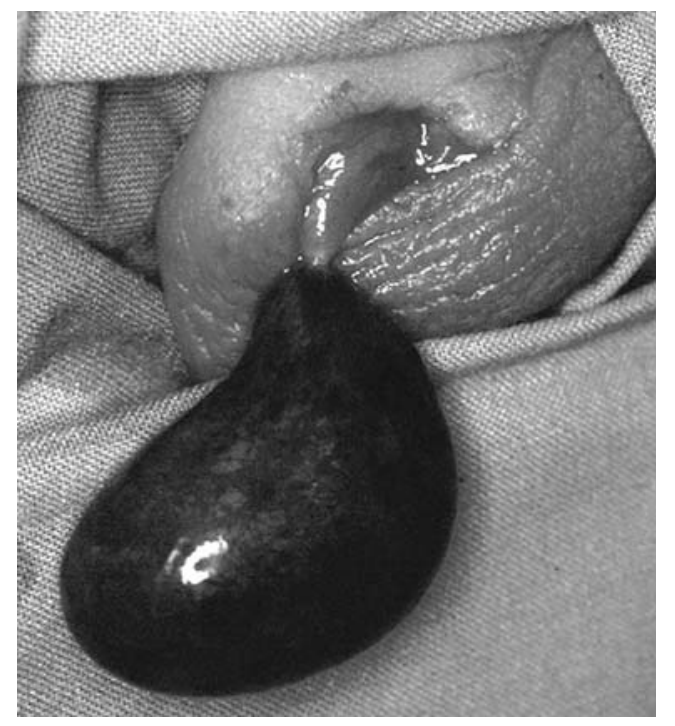

Figure 1 - Gross appearance of perinatal torsion. Although appearance of extravaginal torsion varies from case to case, in general, after opening dartos muscle, intrascrotal contents appear as a dark mass containing the dying testis. intravaginal torsion where torsion occurs intravaginaly, in cases of EVT, twists of the spermatic cord are located outside the cavity created by the two layers of tunica vaginalis (Figure-1,2 and 3). Finally, although due to the usual chronic character of this antenatal event in EVT scrotal anatomy is found greatly altered, and identification of particular anatomical structures within the twisted mass becomes very difficult, testicular attachments with the parietal layer of tunica vaginalis were in fact present, an observation in accordance with most other anatomical references on the subject (Figure-3) (3-5). Each theory on surgical anatomy of EVT must be consistent with these gross characteristics.

\section{Theories on the Anatomical Basis of Extravaginal Torsion}

The literature review revealed 2 controversial anatomical definitions of EVT $(6,7)$. These describe an extravaginal torsion within dartos muscle, including all layers of the spermatic cord and an extravaginal torsion within internal spermatic fascia, outside the parietal layer of tunica vaginalis (Figure-4). For discriminative reasons we will refer to them as EVT outside or inside the cremaster muscle.

\section{Torsion Outside Cremaster Muscle}

There is evidence that in perinatal period of life a lack of attachments of the entire scrotal contents with the scrotal wall is present, allowing testis and its tunics to demonstrate an unusual mobility. Cooper (1830) and Jerkings et al. (1983) first proposed this lack of attachment because of the ease with which the intrascrotal contents could be lifted out in newborns, without tearing any fascial attachments $(5,6)$. More precisely, external spermatic fascia does not seem to be adherent to the dartos muscle. These attachments are suggested to be formed during the first 7 to 10 days of life anchoring the spermatic cord into the scrotum (7). Numerous authors use this fact to report that EVT is predisposed by this lack of attachments and accordingly, twists of the cord occur outside cremaster muscle and its fascia (external spermatic fascia), within dartos muscle, including all layers of spermatic cord (6-9) (Figure-4a). According to this point of view, EVT should become impossible after the first days of life, when connection of testicular tu- 


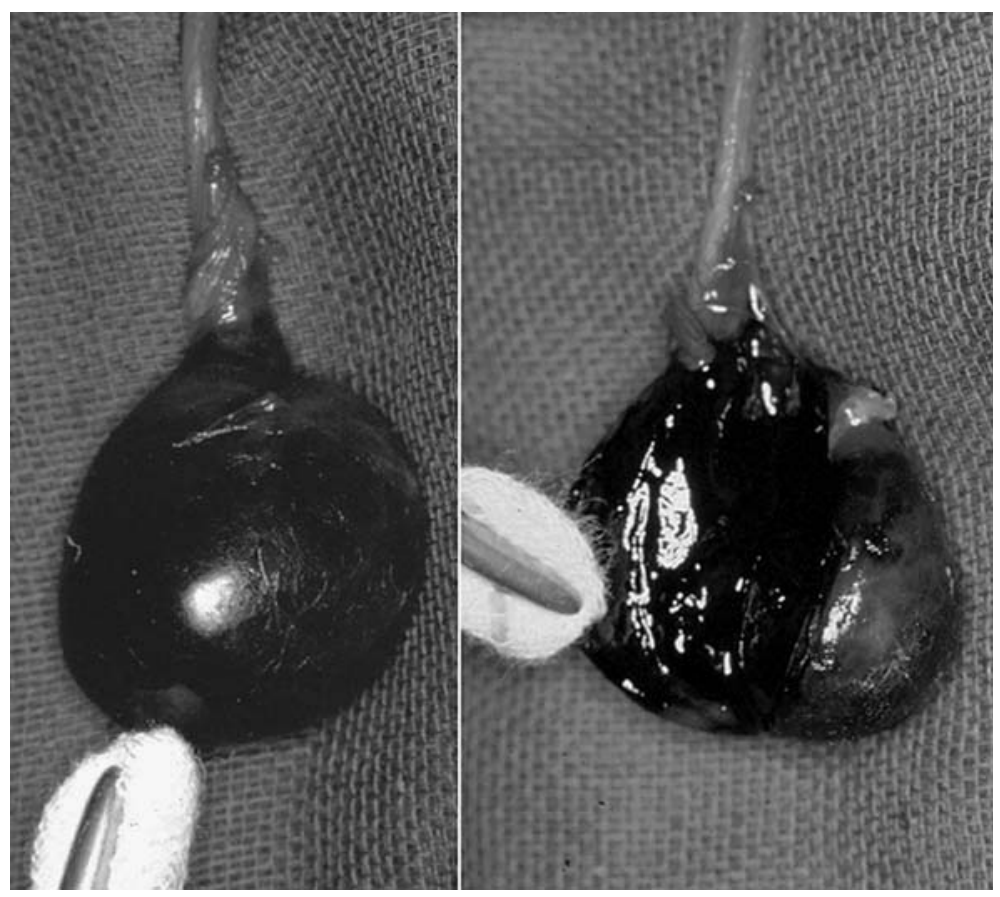

Figure 2 - Hemorrhagic fluid from ischemic testis, restricted inside external spermatic fascia is a usual finding during surgery. The fact that the outer layer always sequesters the inner fluid indicates that this layer remains unaffected from the ischemic event. During dissection of twisted mass identification of particular structures is considered very difficult, due to the chronic character of this antenatal event.

nics with the scrotum is established. Gross appearance of EVT reinforce the above mentioned theory, since the black necrotic twisted mass noted immediately on opening the dartos muscle clearly indicates a torsion involving all layers of spermatic cord (Figure-3).

However, this perinatal lack of attachments is a normal condition appearing in all newborns up to 7-10 days after birth. According to Noseworthy (2002) the above mentioned explanation of EVT poorly supports the relatively rare occurrence of this condition. If lack of fixation in all newborns was a predisposing factor for EVT, this should lead to a considerably higher incidence of EVT during the perinatal life (10). In addition, EVT has been reported in older patients at 12-14 years of age when such attachments are considered to be well established (11-13). In such cases, EVT in the presence of connection between dartos and external spermatic fascia remains unexplained by the examined theory, raising doubts on its validity.

As regards gross appearance, given that the outer membrane layers of the spermatic cord are very thin and transparent it is almost impossible by observation alone to distinguish the exact twisted layer of spermatic cord. In contrast, histological ischemic lessons outside tunica vaginalis observed in the removed specimens after orchidectomy has never, to our knowledge, been previously documented. Furthermore, the fact that hemorrhagic fluid is always confronted within an outer membrane layer, indicates that this layer (that is the external spermatic fascia and probably inner layers too) remains intact and is not included in the ischemic tissues (Figure-4).

Taking all the above factors into consideration, in cases of perinatal EVT doubts on whether or not external spermatic fascia is included in the twisted mass are reveled, while the mechanism that describes an EVT outside cremaster muscle including all layers of the spermatic cord remains to be defined.

\section{Torsion Inside Cremaster Muscle}

The second theory to explain EVT is that in the full-term infant, the spermatic cord and testis are free to rotate within the inguinal canal and scrotum, 


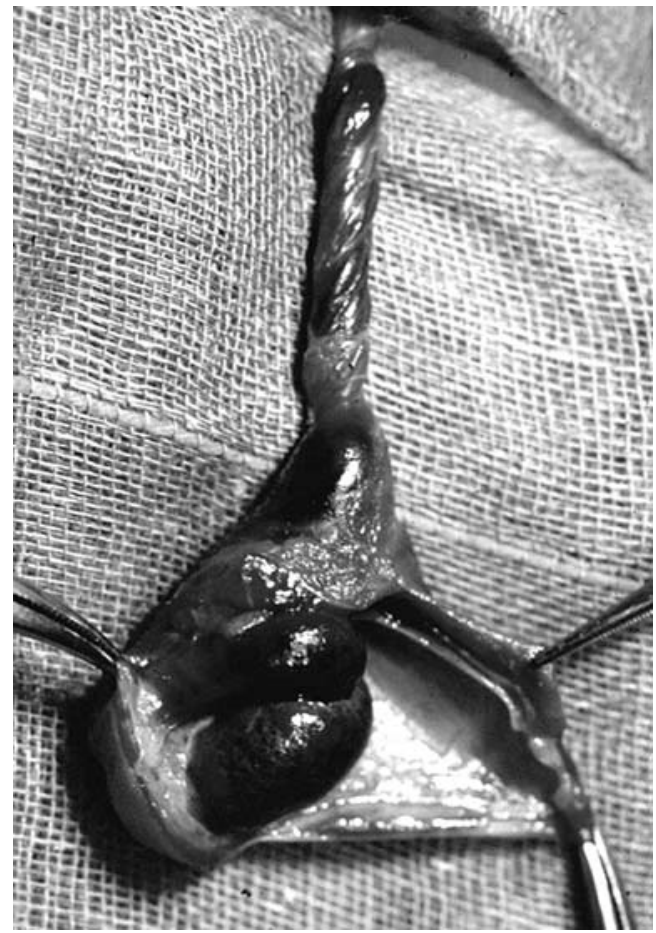

Figure 3-Twists of spermatic cord in case of extravaginal torsion (EVT) are located much more proximal compared with intravaginal testicular torsion. Moreover, in contrast with bell clapper deformity appearing in cases of intravaginal torsion, in EVT testicular attachments with tunica vaginalis appear to be present.

due to lack of attachment between the testicular tunica vaginalis and the scrotum. Most authors refer to this theory $(12,14-18)$ (Figure-4b). In matters of gross appearance, the smooth membrane layer usually covering the twisted mass, sequestering the underlying hemorrhagic fluid reinforce this theory, indicating that torsion occurs in an inner rather than an external spermatic layer. However, we have reasons to believe that this theory is based on a misinterpretation of the definition "lack of fixation of tunica vaginalis to the scrotum" as defined by Cooper (1830), which has been subsequently uncritically copied by most authors (5). It has usually been referred to as, "due to the recent descent of the gonad, there is an extreme mobility of tunica vaginalis within the scrotum before fixation of tunica vaginalis to the scrotal wall" $(15,16)$, or "there is lack of firm attachment of parietal layer of tunica vaginalis with the scrotum" (2). However, liter- ally, parietal layer of tunica vaginalis is never fixed to the scrotum, but its outer associated membranes (cremaster muscle and fascias) will. Therefore, inadequate fixation of tunica vaginalis to the scrotum is a term incorrectly used for the description of the normal lack of connections of the entire scrotal contents with

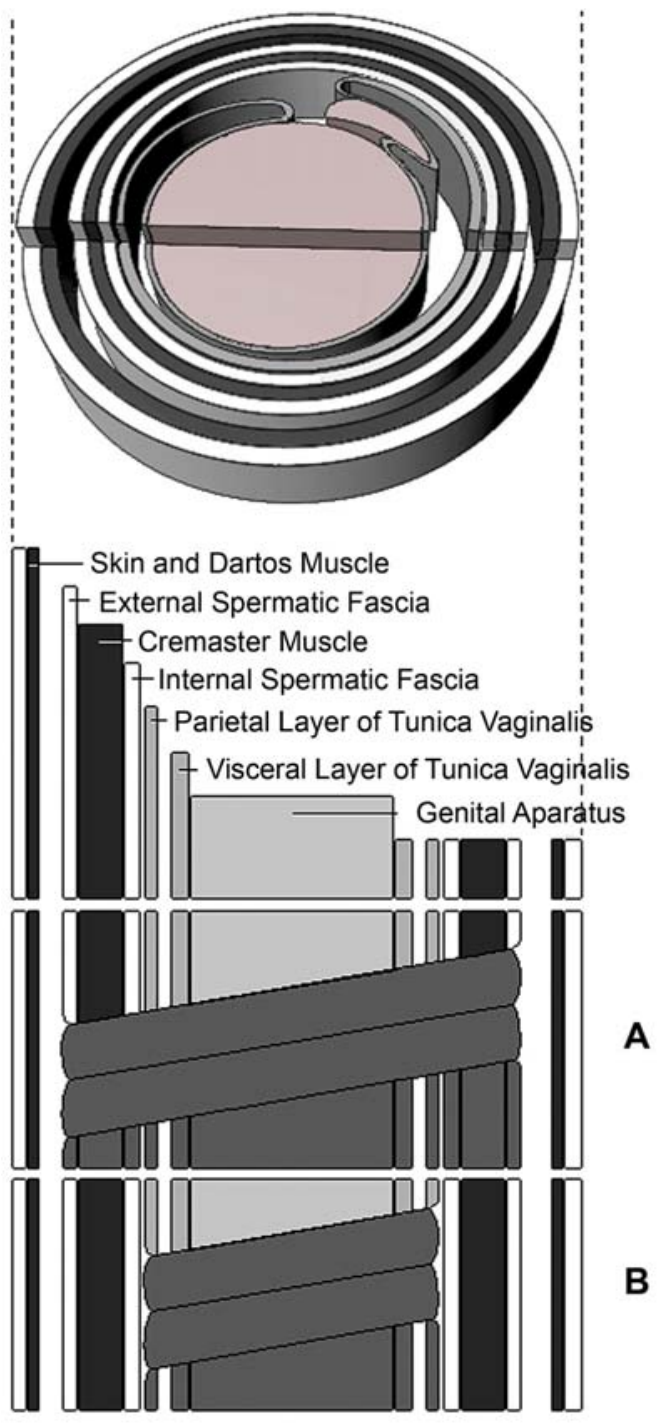

Figure 4-Diagrammatic illustration of scrotal membrane layers outside genital apparatus (testis, epididymis, spermatic cord and spermatic vessels) and proposed anatomical explanations of extravaginal torsion (EVT). Ischemic tissues under torsion are demonstrated by the same color. A)- EVT outside cremaster muscle. B)- EVT inside cremaster muscle. 


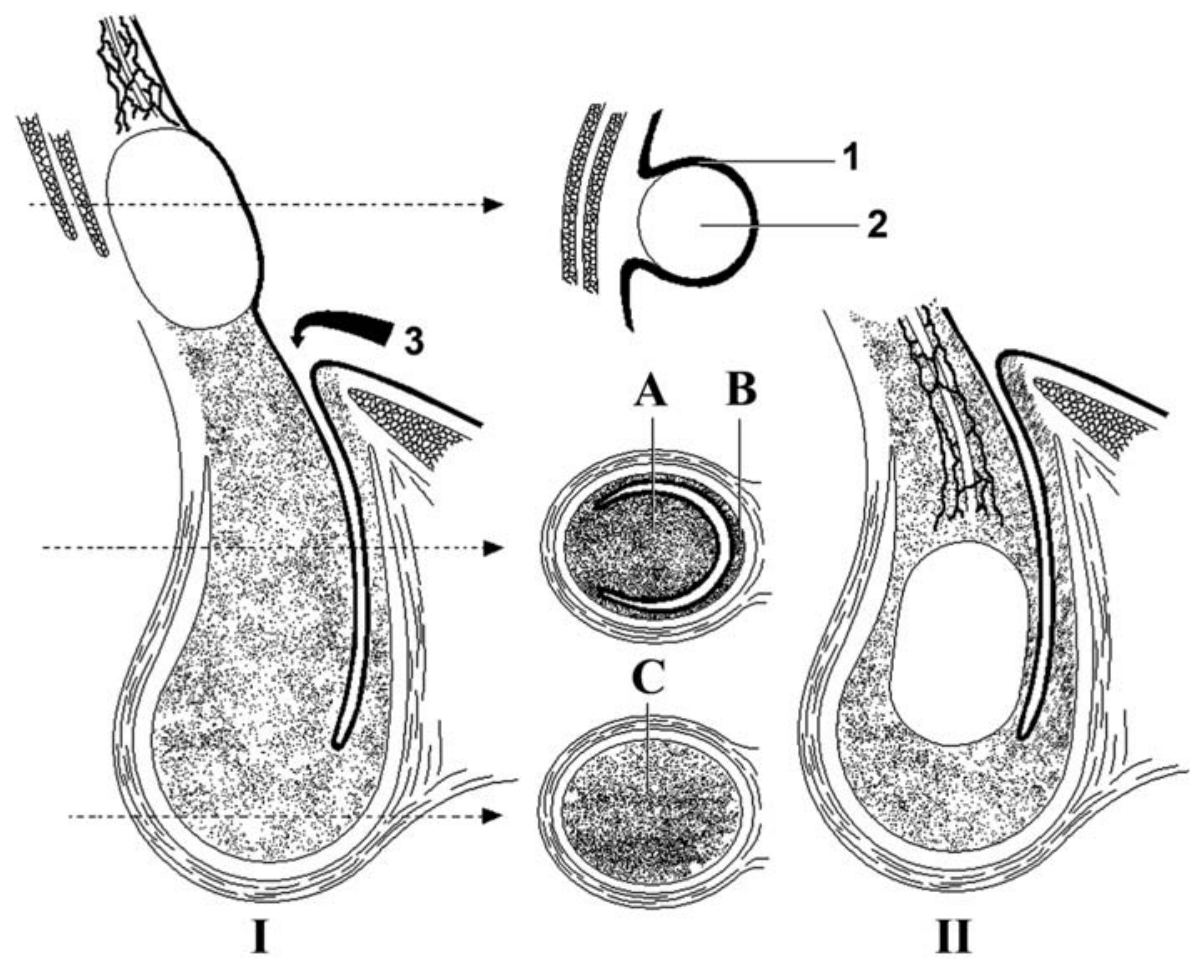

Figure 5 - Schematic illustration of the anatomical associations between testis, gubernaculum and peritoneum before (I) and after (II) the descent of the testis. $A=$ plica gubernaculi, $B=$ Pars vaginalis gubernaculi, $C=$ Pars infravaginalis gubernaculi, 1 = peritoneum, 2 = gonad, 3 = processus vaginalis.

the scrotal wall in the first days of life, as described by Cooper (5).

Moreover, not only, perinatal lack of attachment between testicular tunica vaginalis and its outer associated membranes in the scrotum have never, in fact, been documented, but also there is no obvious etiological reason to explain why such a lack should be present in the first place. During embryogenesis, both the parietal layer of tunica vaginalis (derivative of the peritoneum forming the parietal layer of processus vaginalis) and the derived by the pars vaginalis gubernaculum outer associated membranes (internal spermatic fascia, cremaster muscle and external spermatic fascia) were never separate (19). This firm relationship negates the possibility of a perinatal absence of such attachments (Figure-5).

On the contrary, even assuming an absence of attachments between tunica vaginalis and internal spermatic fascia, torsion outside tunica vaginalis could not possibly occur. Given that in EVT testicular anatomy is considered to be normal (absence of bell clapper deformity) in scrotal and inguinal region the testis, epididymis, spermatic vessels and vas deference lie posteriorly connected with the internal spermatic fascia through a wide mesentery (mesogonadal - mesorcheon) and cannot move freely (20) (Figure-6).

These factors prove that, there is no embryological basis to support a perinatal lack of tunica vaginalis attachments with the internal spermatic fascia, while as in every scrotum with normal anatomy, in cases of EVT, rotation inside cremaster muscle cannot occur (21).

\section{COMMENTS}

The validity of the anatomical basis of EVT has been previously questioned. Mushat (1932) in his work on mechanism of testicular torsion raised 


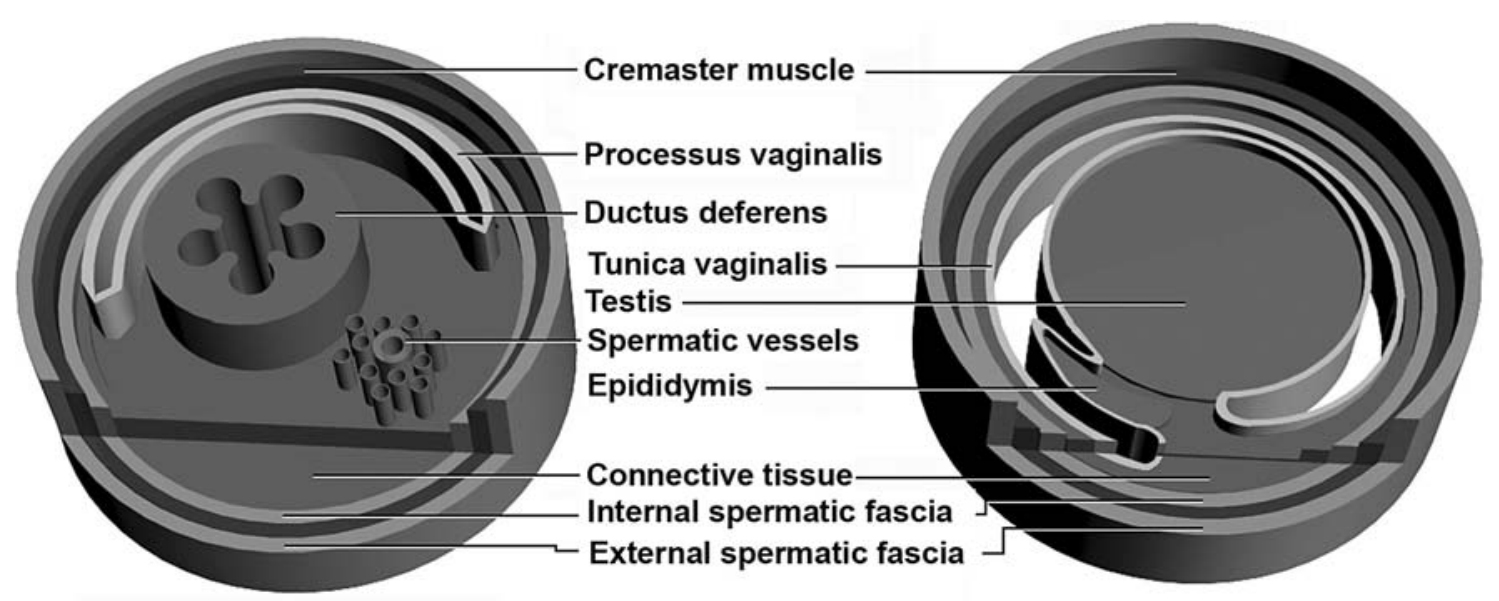

Figure 6 - Diagrammatic illustration of normal anatomy in inguinal and scrotal region. Posterior, the extraperitoneal connective tissue anchors through testicular mesentery the functional elements to internal spermatic fascia. Skin and dartos muscle are not shown.

doubts on whether EVT was actually possible (21). Additional doubts on whether current anatomical interpretation is correct are derived from data suggesting the possibility of the existence of a bell clapper deformity in case of perinatal torsion. As stated above and demonstrated by our photographic data EVT is considered to be characterized by connection of testis with tunica vaginalis, in contrast with intravaginal torsion where posterior attachment of testis with tunica vaginalis is absent and scrotal structures demonstrate the bell clapper deformity. Investigation of contralateral testes in cases of vanishing testis syndrome, a condition representing the final effect of antenatal torsion revealed the presence of a contralateral bell clapper deformity in the remarkable percentage of $86 \%$ of cases $(15,22-25)$. Given that bell clapper deformity is usually bilateral, existence in the ipsilateral, where antenatal torsion has occurred, of a bell clapper deformity as well before the vanishing event is very possible. Therefore, the question whether presence of connection between testis and tunica vaginalis in case of EVT represents normal anatomy or fibrotic connections of an underlying bell clapper deformity due to the chronic character of this antenatal event remains to be defined. This fact would reinforce the majority of authors, who support an EVT within dartos muscle, though under a different hypothesis than the one proven to be incorrect by our study.

\section{CONCLUSION}

In summary, the two most commonly accepted anatomical definitions of perinatal testicular torsion namely an extravaginal torsion within dartos muscle, including all layers of spermatic cord and an extravaginal torsion outside parietal layer of tunica vaginalis within internal spermatic fascia remain questionable. In the first case, although there is evidence of perinatal lack of attachments between external spermatic fascia and dartos muscle, such torsion has not been proved with certainty. On the contrary, a large body of literature argues against this explanation. In the second case, doubts on whether there is lack of attachments between testicular tunica vaginalis and scrotum have been revealed. Yet, even if such a lack was actually present, testicular torsion inside internal spermatic fascia would still be impossible, since genital apparatus remains fixed by its wide mesorchium to external membrane layers of the scrotum. Finally, suspicions regarding the existence of a bell clapper deformity in all cases of EVT were raised, a fact confronting the current understanding of the condition. It is concluded that the prevalent anatomical definitions of EVT fail to explain adequately the phenomenon of perinatal torsion and to allow an evidence based documentation of the indicated treatment modality. EVT still remains a 
condition of unknown etiology, pathophysiology and surgical anatomy and thus further investigation in the field is required.

\section{CONFLICT OF INTEREST}

None declared.

\section{REFERENCES}

1. Waldschmidt J: Hodentorsion. In: Waldschmidt J, Hamm B, Schier F (ed.), Das acute Skrotum. Stuttgard - Verlag, Hippokrates. 1990; pp. 27-48.

2. Herman A, Schvimer M, Tovbin J, Sandbank J, Bukovski I, Strauss S: Antenatal sonographic diagnosis of testicular torsion.Ultrasound Obstet Gynecol. 2002; 20: 522-4.

3. Whitaker RH: Diagnoses not to be missed. Torsion of the testis. Br J Hosp Med. 1982; 27: 66-9.

4. Mishriki SF, Winkle DC, Frank JD: Fixation of a single testis: always, sometimes or never. Br J Urol. 1992; 69: 311-3.

5. Cooper Sir Astley: Observations on the structure and disease of the testis. Longman, London, 1830.

6. Jerkins GR, Noe HN, Hollabaugh RS, Allen RG: Spermatic cord torsion in the neonate. J Urol. 1983; 129: 121-2.

7. Sheridan WG, Davies DG: Extravaginal testicular torsion. Br J Clin Pract. 1988; 42: 128-30.

8. Kay R, Strong DW, Tank ES: Bilateral spermatic cord torsion in the neonate. J Urol. 1980; 123: 293.

9. Junnila J, Lassen P: Testicular masses. Am Fam Physician. 1998; 57: 685-92.

10. Noseworthy J: Testicular torsion. In: Ashcraft K.W (ed.), Pediatric Surgery 3rd ed. WB Saunders, Philadelphia, 200; 674-80.

11. Das S, Singer A: Controversies of perinatal torsion of the spermatic cord: a review, survey and recommendations. J Urol. 1990; 143: 231-3.

12. Barker K, Rapeer FP: Torsion of the testis. Br J Urol. 1964; 36: 35-41.

13. Johnston JH: The testicles and the scrotum. In: DI Williams (ed.), Pediatric Urology. London, Q Butterworths. 1968; pp. 450-74.

14. Sorensen MD, Galansky SH, Striegl AM, Koyle MA: Prenatal bilateral extravaginal testicular torsion--a case presentation. Pediatr Surg Int. 2004; 20: $892-3$
15. Belman AB, Rushton HG: Is the vanished testis always a scrotal event? BJU Int. 2001; 87: 480-3.

16. Al-Salem AH: Intra-uterine testicular torsion: early diagnosis and treatment. BJU Int. 1999; 83: 1023-5.

17. Traubici J, Daneman A, Navarro O, Mohanta A, Garcia $\mathrm{C}$ : Original report. Testicular torsion in neonates and infants: sonographic features in 30 patients. AJR Am J Roentgenol. 2003; 180: 1143-5.

18. Arena F, Nicotina PA, Scalfari G, Visalli C, Arena S, Zuccarello B, et al.: A case of bilateral prenatal testicular torsion: Ultrasonographic features, histopathological findings and management. J Pediatr Urol. 2005; 1: 369-72.

19. Pham SB, Hong MK, Teague JA, Hutson JM: Is the testis intraperitoneal? Pediatr Surg Int. 2005; 21: 231-9.

20. Hollinshead WH: The perineum. In: Hollinshead WH (ed.), Anatomy for Surgeons Vol 2. 2nd ed. New York, Harper and Row. 1971; pp. 853-68.

21. Mushat M: The pathological anatomy of testicular torsion; explanation of its mechanism. Surgery, Gynecology and Obstetrics. 1932; 54: 758-63.

22. Gong M, Geary ES, Shortliffe LM: Testicular torsion with contralateral vanishing testis. Urology. 1996; 48: 306-7.

23. Belman AB, Rushton HG: Is an empty left hemiscrotum and hypertrophied right descended testis predictive of perinatal torsion? J Urol. 2003; 170: 1674-5; discussion 1675-6.

24. Bellinger MF: The blind-ending vas: the fate of the contralateral testis. J Urol. 1985; 133: 644-5.

25. Harris BH, Webb HW, Wilkinson AH Jr, Stevens PS: Protection of the solitary testis. J Pediatr Surg. 1982; 17: 950-2.

Accepted after revision: July 7, 2008

\section{Correspondence address:}

Dr. Iason D. Kyriazis

22 Xatzikonstanti St. Papagos

PC 15669, Athens, Greece

Fax: + $30210656-0220$

E-mail: jkyriazis@gmail.com 


\section{EDITORIAL COMMENT}

Most cases of fetal and neonatal testicular torsion are diagnosed at birth either by absence of the testis in the scrotum or inguinal region (vanishing testis), or by the presence of a hard testis fixed to the scrotal skin. These cases are thought to be caused by an extravaginal torsion of the spermatic cord (EVT), due to inadequate attachments between the layers of the spermatic cord, usually completed only after few weeks of life. Despite prompt surgical exploration of the ischemic testes in the neonatal period, their salvage rate is very low, and the real debate is if early contralateral testicular fixation is warranted. Cases of testicular torsion occurring later, in previously normal testes, are also caused by an intravaginal torsion of the spermatic cord, by the bell-clapper deformity, that usually is observed also in the contralateral testis (1). In these cases, since the salvage rate of the affected testis rises to almost 50\%, emergency surgical exploration is always recommended, and must include the contralateral testicular fixation (2).

The work by Dr Kyriazis and associates evaluates the anatomical definitions of the perinatal EVT, based mainly on a thorough review of the literature. The bibliographical survey is well performed, and the authors elegantly discuss the two theories on the anatomical basis of the EVT, the one occurring inside, and the other outside the cremaster muscle. They also propose an evaluation of a photographic data from 14 previously operated cases. Unfortunately, although illustrative, this evaluation is superficial and presented without scientific methodology. Furthermore, they present no pathological data of their cases that could give support to any of the two mentioned theories.

Although this work does not address the issue of the management of EVT, I encourage the authors to review their material and include more significant information of their cases, including age of the patients, management of the contralateral testes and pathological data, that would surely enrich the scarce literature on the subject.

\section{REFERENCES}

1. Favorito LA, Cavalcante AG, Costa WS: Anatomic aspects of epididymis and tunica vaginalis in patients with testicular torsion. Int Braz J Urol. 2004; 30: 4204.

2. Sorensen MD, Galansky SH, Striegl AM, Mevorach R, Koyle MA: Perinatal extravaginal torsion of the testis in the first month of life is a salvageable event. Urology. 2003; 62: 132-4.

\section{Dr. Francisco Tibor Dénes \\ Section of Pediatric Urology \\ University of Sao Paulo, USP \\ Sao Paulo, SP, Brazil \\ E-mail:ftdenes@terra.com.br}

amination be done in the immediate postpartum period as well as prior to discharge. This will obviate any delay in diagnosis and treatment of IUTT since the majority of them will manifest in the immediate postpartum period (2). IUTT is a very rare condition that may also be difficult to recognize when seen for the first time and so it may be missed or confused with other conditions. To obviate delay in diagnosis, physicians caring for these patients should be aware of this. 
Since its first description, controversies continue to exist regarding: (1) its exact cause, (2) the need for urgent exploration and (3) the necessity for contra lateral orchidopexy.

The cause as well as the anatomical basis of IUTT is not known. In this issue, Kyriazis et al. in an extensive review attempted to evaluate the anatomical basis of intrauterine torsion. Although IUTT is usually a prenatal event, the exact timing and duration of torsion are not known and there are reports of prenatally diagnosed torsion. Tripp and Homsy reported a case of bilateral torsion diagnosed prenatally at 35 weeks gestation and Hubbard et al. reported a case of unilateral torsion diagnosed at 35.5 week gestation $(3,4)$. On the other hand, and although most cases of IUTT are apparent at birth, there are reports of torsion occurring after delivery or within the first week after birth (5). It is believed that IUTT is the main cause of monorchidism, which is supported by the fact that a vas deference, epididymis, calcification or hemosiderine pigmentation is present in about $90 \%$ of the cases (6). In cases of IUTT, controversy still continues regarding the urgency for surgical exploration as well as the need for contra lateral orchidopexy. Some investigators advocate delayed operation, and consider this not an emergency (7). This is to obviate the anesthetic risk imposed on the neonate as well as the low salvage rate of these testes. If such a policy is adopted, then these patients should not be operated on at all as ultimately the affected testis will atrophy. On the contrary, these patients are healthy, of good birth weight and without any other associated anomalies that impose an anesthetic risk (2). Keeping this in mind as well as the hope of testicular preservation, we like others adopted a policy of early surgical intervention $(2,8)$. Olguner et al. reported a patient at the postnatal $28^{\text {th }}$ hour with right scrotal erythema and swelling. Emergency technetium Tc 99m pertechnetate scintingraphy showed hypo perfusion in both sides and because the patient underwent surgery immediately, the left testis was judged viable, treated by means of detorsion and saved while the right testis was necrotic (8). Early surgical exploration also establishes the diagnosis and excludes other rare causes such as benign and malignant tumors and traumatic hematocele.

Another controversial point is whether contra lateral orchidopexy is justified. Some investigators suggested that since predisposing factors are lacking in extravaginal torsion, there is no need for contra lateral orchidopexy (6). This however is difficult to establish. On the other hand, the increasing number of reported cases with bilateral intrauterine torsion supports a predisposing factor $(3,8-10)$, and although asynchronous bilateral torsion is rare, it can however occur at any time and has been reported as early as 48 hours after torsion on the other side (10). To obviate the risk of anorchia, we like others advocate routine and simultaneous contra lateral exploration and orchidopexy. This is a simple procedure, has no or minimal morbidity and safeguards against contra lateral torsion.

\section{REFERENCES}

1. Taylor MR: A case of testicular strangulation at birth, castration, recovery. Br Med J. 1897; 1: 458.

2. Al-Salem AH: Intrauterine testicular torsion: a surgical emergency. J Pediatr Surg. 2007; 42: 1887-91.

3. Tripp BM, Homsy YL: Prenatal diagnosis of bilateral neonatal torsion: a case report. J Urol. 1995; 153: 1990-1.

4. Hubbard AE, Ayers AB, MacDonald LM, James CE: In utero torsion of the testis: antenatal and postnatal ultrasonic appearances. Br J Radiol. 1984; 57: 644-6.

5. Burge DM: Neonatal testicular torsion and infarction: aetiology and management. Br J Urol. 1987; 59: 70-3.

6. Lamesch AJ: Monorchidism or unilateral anorchidism. Langenbecks Arch Chir. 1994; 379: 105-8.

7. Cumming DC, Hyndman CW, Deacon JS: Intrauterine testicular torsion: not an emergency. Urology. 1979; 14: 603-4.

8. Olguner M, Akgür FM, Aktuð T, Derebek E: Bilateral asynchronous perinatal testicular torsion: a case report. J Pediatr Surg. 2000; 35: 1348-9.

9. Weingarten JL, Garofalo FA, Cromie WJ: Bilateral synchronous neonatal torsion of spermatic cord. Urology. 1990; 35: 135-6.

10. LaQuaglia MP, Bauer SB, Eraklis A, Feins N, Mandell J: Bilateral neonatal torsion. J Urol. 1987; 138: 1051-4.

Dr. Ahmed H. Al-Salem Consultant Pediatric Surgeon Maternity ad Children Hospital Dammam, Saudi Arabia E-mail:ahalsalem@hotmail.com 


\section{EDITORIAL COMMENT}

The authors challenge established anatomical and pathological principles of "extravaginal" testicular torsion through a discussion on the clinical findings, a literature review and a focused anatomical discussion. The importance of this discussion lies within the implications for clinical management in this group. The debate within pediatric surgical literature between the active exploration of the perinatal torsion and its conservative management is firmly grounded in the surgical precepts that intra and extra vaginal torsions are separate anatomical and surgical anomalies.

The paper debunks the accepted theories of extravaginal torsion. The authors argue that the simple lack of perinatal attachments which is the clinical norm in the first seven to ten days does not equate to the relative infrequency of the condition. The absence of a clear definition of extravaginal torsion and the specter of presence of bell clapper deformity leads to a requirement for a much more aggressive surgical management of this condition.

Despite the relative infrequency of the asynchronous torsion in the literature as pediatric urologists we all seem to have one or more of these patients in our own units leading to real concerns of under reporting (1). A significant body of opinion argues against conservative management due to incidence of asynchronous events (2-4). Baglaj et al. identified 48 cases of bilateral perinatal torsions in the literature (5). Synchronous torsion occurred in $67 \%$ thus asynchronous torsion occurred in 33\%. Urgent exploration of the torted testis and empiric exploration and orchidopexy for the contralateral testis is recommended in all cases of perinatal torsion. Parental counseling which explains the relatively low salvage rate and the high asynchronous torsion rate is warranted.

The challenge for pediatric surgeons is to examine all the excised perinatal testicles that in order to delineate the pathology. Further anatomical studies are required on the scrotal anatomy of neonates with fully descended testes who die in the perinatal period in order to define the normal anatomical attachments of the testes.

\section{REFERENCES}

1. Beasley SW, McBride CA. The risk of metachronus (asynchronous) contralateral torsion following perinatal torsion. N Z Med J. 2005; 118: U1575.

2. Cuervo JL, Grillo A, Vecchiarelli C, Osio C, Prudent L: Perinatal testicular torsion: a unique strategy. J Pediatr Surg. 2007; 42: 699-703.

3. Yerkes EB, Robertson FM, Gitlin J, Kaefer M, Cain MP, Rink RC: Management of perinatal torsion: today, tomorrow or never? J Urol. 2005; 174: 1579-82; discussion 1582-3.

4. Sorensen MD, Galansky SH, Striegl AM, Mevorach R, Koyle MA: Perinatal extravaginal torsion of the testis in the first month of life is a salvageable event. Urology. 2003; 62: 132-4.

5. Baglaj M, Carachi R: Neonatal bilateral testicular torsion: a plea for emergency exploration. J Urol. 2007; 177: 2296-9.

Dr. Feilim Murphy Consultant Paediatric Urologist Department of Paediatric Surgery and Urology St George's Hospital, London, United Kingdom Email:feilimmurphy@ireland.com 